\title{
The Influence Law of Freeze-thaw Temperature Difference for the Strength Parameter of Remolded Loess
}

\author{
Kangfeng Yuan ${ }^{a}$ \\ (a, Key Lab of Highway Construction \& Maintenance Technology in Loess Region, Ministry of \\ Transport, PRC, b, Shanxi Key Laboratory of Highway Construction \& Maintenance Technology \\ in Loess Region,Shanxi Transportation Research Institute, Shanxi, Taiyuan 030006, China) \\ ayuankangfeng@163.com
}

\begin{abstract}
Key words : freeze-thaw; temperature difference; Remolded Loess; strength parameter; triaxial shear test

Abstract : At present, the research is not enough for the correlation of loess strength parameter and freeze-thaw temperature difference in domestic.The paper aims how the change of freeze-thaw temperature difference influence the stress characters of remolded loess by consolidated drained triaxial shear test for.The results showed that: the strength parameter of remolded loess decreases with the increasing of freeze-thaw temperature difference.The reduce of strength parameter $\mathrm{c}$ is obvious with the increasing freeze-thaw temperature difference. The reduce of strength parameter $\varphi$ is not obvious with the increasing freeze-thaw temperature difference.
\end{abstract}

\section{Introduction}

The influence of freeze-thaw on the engineering properties of soil can be roughly analyzed from two aspects: the soil water properties, the physical properties and the soil mechanical properties. Jiang Zong-bin et $\mathrm{a}^{[1]}$ think that under the same times of freezing-thawing cycles, shear strength increases with increasing of confining pressure. Under the sameconfining pressure, internal frictional angle, cohesive strengthand shear strength present the tendency of reducing first and thenincreasing with the increase of the times of freezing-thawing cycles, however moisture content presents the tendency of increasing first then reducing with the increase of the times of freezing-thawing cycles. The turning point is about in the position of 7 times. Wang Jing et al ${ }^{[2]}$ think that the elastic modulus increases with confining pressure increase for the same kind of soil under the same freeze-thaw cycles.Elastic modulus with the same confining pressure decreases with the of freeze-thaw cycles; Under the same confining pressure and the same freeze-thaw cycles, elastic modulus increases with the plasticity index. The exponential function is adopted for multiplenonlinear fitting. The relationship between elastic modulus and confining pressure, plasticity index, freeze-thaw cycles is obtained and shows a good correlation. WEi Yong-xing et $\mathrm{al}^{[3]}$ think that the stability calculation of embankment slope in permafrost regions not only refers to ordinaryslope analysis methods, but also considers the time factor. In addition, the stability reinforcement of embankment slope still can take the following methods, such as the selection of filter, the geogrid, the anti - slide piles, and so on. However, for the law of strength 
parameter and freeze-thaw, there is rare research on the remolded loess ${ }^{[4]-[10]}$.

The triaxial tests are the commonly methods to study the strength characteristics. With the help of consolidated drained triaxial tests to research the characteristics of remolded loess for different freeze-thaw temperature difference. The research have certain theoretical significance for the study of loess freeze-thaw characteristics. At the same time, it provides reference for the future research of loess strength.

\section{The loess of test}

The loess of tests is taken from certain foundation at the Jinnan district, in a depth of $5 \mathrm{~m}$ below the surface, which is brownish yellow, silty clay, soil evenly, with a small amount of worm holes. The natural moisture content of soil samples was $9.6 \%$.

\section{Test Instruments and Test Method}

\section{Test Instruments}

The test instrument is the conventional triaxial shear apparatu. The pressure will directly load to the roof through counterproductive of fixed beam gantry, The steel ring and pressure sensor will measure pressure.

The test instrument of freeze-thaw is the constant temperature and humidity box which is produced by a instrument factory of nanjing. The temperature control precision is higher.

\section{Test Method}

Prepare four group remolded triaxial specimen (diameter $3.91 \mathrm{~cm}$, height $8 \mathrm{~cm}$ ). The freezing temperature is 20 degrees below zero, the time is 12 hours, the thawing temperature is 5 degrees, 10 degrees, 15 degrees, 20 degrees, that is, the temperature difference is 25 degrees, 30 degrees, 35 degrees, 40 degrees, the time is 12 hours. Configure pressure was separate $100 \mathrm{kPa}, 200 \mathrm{kPa}$, $400 \mathrm{kPa}$ for consolidated drained shear test of Each group sample(the number is four); specimen installed before applying confining pressure, open the drain valve to consolidation, start motor to cut after the end of consolidation. The final shutdown standard is to see the soil samples which have obvious cracks or dislocation or axial deformation reaches $12 \mathrm{~mm}$.

\section{Test Results and Analysis}

The influence of freeze-thaw temperature difference on strength characteristics of remolded loess

According to formula 1:

$$
\tau=c+\sigma \tan \phi
$$

The law of remolded loess shear strength changing with freeze-thaw temperature difference is indicated in figures 1 to 4 : 

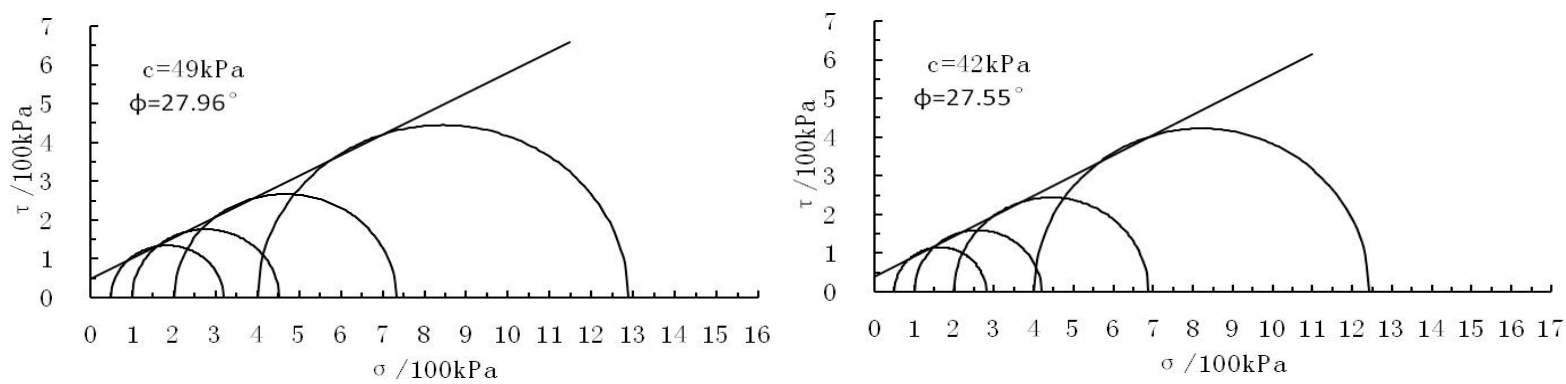

Figure1.Strength line for temperature difference Figure2.Strength line for temperature difference
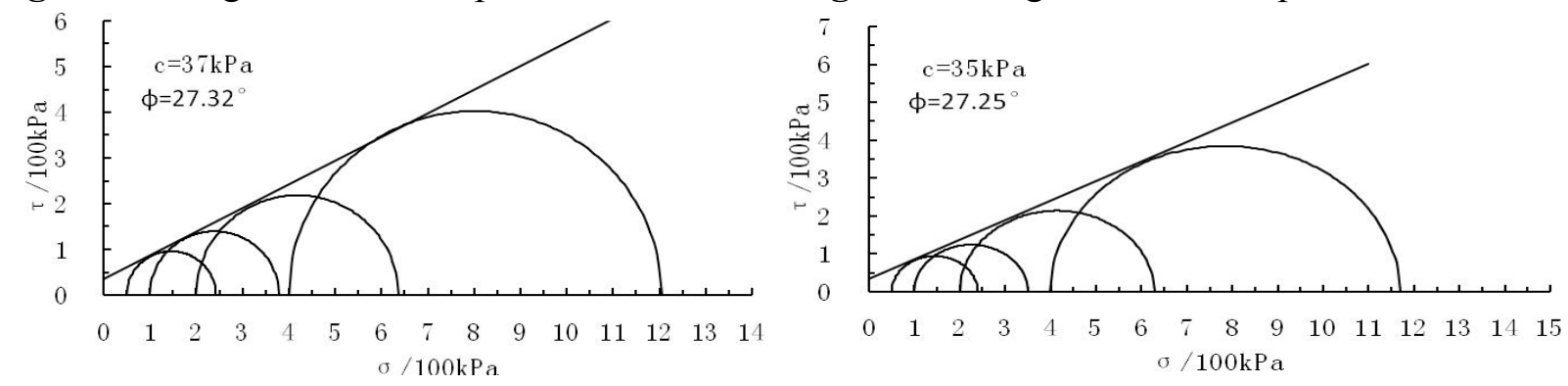

Figure3.Strength line for temperature difference Figure4.Strength line for temperature difference

Figure 1-4 show that the strength parameter of remolded loess decreases with the increasing of freeze-thaw temperature difference.

The law of strength parameter changing with freeze-thaw temperature difference for remolded loess

The law of remolded loess strength parameter under different freeze-thaw temperature difference is indicated in figures 5 :

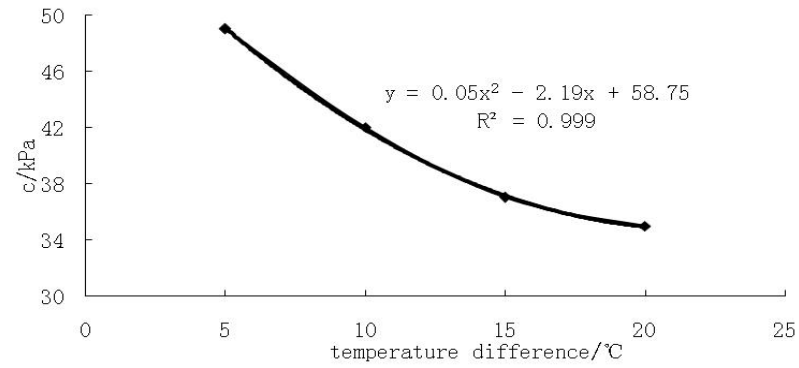

(a) Parameter c

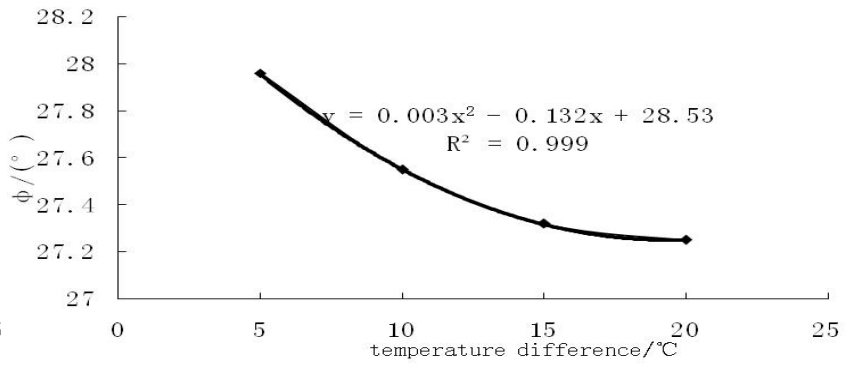

(b) Parameter $\varphi$

Figure 5. Relationship between strength parameter and freeze-thaw temperature difference

Figure 5 show that with the increase of freeze-thaw temperature difference, the strength reduce. The reduce of strength parameter $\mathrm{c}$ is obvious with the increasing freeze-thaw temperature difference. The reduce of strength parameter $\varphi$ is not obvious with the increasing freeze-thaw temperature difference.

According to Figure 5,the relationship of strength parameter and freeze-thaw temperature difference can be converted to the following formula:

$$
\begin{aligned}
& c=0.05 n^{2}-2.19 n+58.75 \\
& \phi=0.003 n^{2}-0.132 n+28.53
\end{aligned}
$$

According to formula 2, formula 3, to predict the strength parameter for certain freeze-thaw temperature difference, have some theoretical significance for the relation research. 


\section{Conclusions}

In this paper, conventional triaxial test apparatus and the constant temperature and humidity box is applied to study the strength parameter of intact loess under different freeze-thaw temperature difference. The main conclusions are as follows:

(1) the strength parameter of intact loess decreases with the increasing of freeze-thaw temperature difference.

(2) The reduce of strength parameter $\mathrm{c}$ is obvious with the increasing freeze-thaw temperature difference. The reduce of strength parameter $\varphi$ is not obvious with the increasing freeze-thaw temperature difference.

\section{Acknowledgements}

The paper is Sponsored by the Research Project of Shanxi Youth Science and Technology Research Fund [201701D221212].

\section{References}

[1] JIANG Zong-bin, JIANG An-nan. Experimental study on soft soil subgrade under freeze-thaw cycles by triaxial tests in Dalian area [J]. Journal of Dalian Maritime University, 2013, 39(3):117-120.

[2] WANG Jing,LIU Han-bing, WU Chun-li. Influence of freeze-thaw cycles on elastic modulus of subgrade soil with different plasticity indices [J]. Rock and Soil Mechanics, 2012,33(3665-3668).

[3] WEI Yong-xing, XUE Xin-hua. Exploration on the Stabilization of Embankment on Slope in Permafrost Regions [J]. JOURNAL OF RAILWAY ENGINEERING SOCIETY, 2011,12(12) :35-39.

[4] SONG Fei. The study on the stability and deformation mechanism of huazicun loess landslide [J].SHANXI SCIENCE \& TECHNOLOGY of COMMUNICATIONS, 2012,216(3):13-15.

[5] LI Xu-hua.The Rational Slope Type Research on Loess High Slope [J].SHANXI SCIENCE \& TECHNOLOGY of COMMUNICATIONS, 2012,214(1):29-30.

[6] LIAO Xiong-hua, WANG Lei-xiao, ZHANG Ke-xu et,al. An inelasto-plastic constitutive model for soil[J]. Rock and Soil Mechanics, 2002(1):41-45.

[7] Konrad J M. Hydraulic conductivity of kaolinite-silt mixtures subjected to closed-system freezing and thaw consolidation[J].Canadian Geotechnical Journal, 2000, 37(4):857-869.

[8] WANG Yong-zhong, LIU Xiong-jun, AI Chuan-jing et,al. Experimental investigation on shear strength parameters cand $\varphi$ for a temporarily frozen soil in South China [J]. Engineering Journal of Wuhan University, 2010,43(2):198-202.

[9] SHENG Wei-gao,LI Guo-wei,YUAN Jun-ping. Stability analysis of high slopes based on the influence of water content change on soil strength [J]. Advances in Science and Technology of Water Resources, 2009, 29(1):12-15.

[10] Yang Chengsong,He Ping,Cheng Guodong,et al. Testing study on influence of freezing and thawing on dry density and water contentof soil[J]. Chinese Journal of Rock Mechanics and Engineering,2003,22(Supp. 2):2695-2699. 